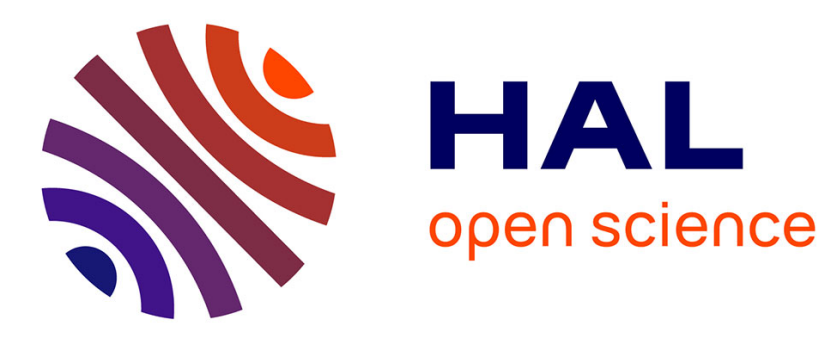

\title{
Structure-sensitive scaling relations among carbon-containing species and their possible impact on CO2 electroreduction
}

\author{
Manuel J Kolb, David Loffreda, Philippe Sautet, Federico Calle-Vallejo
}

\section{- To cite this version:}

Manuel J Kolb, David Loffreda, Philippe Sautet, Federico Calle-Vallejo. Structure-sensitive scaling relations among carbon-containing species and their possible impact on $\mathrm{CO} 2$ electroreduction. Journal of Catalysis, 2021, 395, pp.136-142. 10.1016/j.jcat.2020.12.026 . hal-03414137

\author{
HAL Id: hal-03414137 \\ https://hal.science/hal-03414137
}

Submitted on 4 Nov 2021

HAL is a multi-disciplinary open access archive for the deposit and dissemination of scientific research documents, whether they are published or not. The documents may come from teaching and research institutions in France or abroad, or from public or private research centers.
L'archive ouverte pluridisciplinaire HAL, est destinée au dépôt et à la diffusion de documents scientifiques de niveau recherche, publiés ou non, émanant des établissements d'enseignement et de recherche français ou étrangers, des laboratoires publics ou privés. 


\title{
Structure-sensitive scaling relations among carbon-containing species and their possible impact on $\mathrm{CO}_{2}$ electroreduction
}

\author{
Manuel J. Kolb, ${ }^{1}$ David Loffreda, ${ }^{2}$ Philippe Sautet, ${ }^{3,}$ and Federico Calle-Vallejo ${ }^{1, *}$
}

1 Departament de Ciència de Materials i Química Física, Institut de Química Teòrica i Computacional (IQTCUB), Universitat de Barcelona, Martí i Franquès 1, 08028 Barcelona, Spain.

${ }^{2}$ Univ Lyon, Ens de Lyon, CNRS UMR 5182, Université Claude Bernard Lyon 1, F-69342 Lyon, France.

${ }^{3}$ Department of Chemical and Biomolecular Engineering and Department of Chemistry and Biochemistry, University of California, Los Angeles, Los Angeles, California 90095, United States.

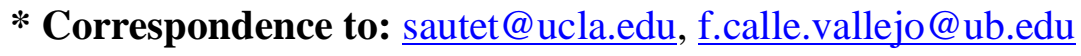

\begin{abstract}
The arduous modelling of reactions at heterogeneous catalysts is greatly simplified when adsorption-energy scaling relations between intermediates exist. The offset of these linear relations is structure-independent when the slope is unity and otherwise depends on the coordination number of the active sites. Here we examine the adsorption of $* \mathrm{C},{ }^{*} \mathrm{CH},{ }^{*} \mathrm{CH}_{2}$, ${ }^{*} \mathrm{CH}_{3}$ and ${ }^{*} \mathrm{COH}$ on five different surface sites of nine transition metals to establish their structure-sensitive scaling relations. Interestingly, we show that the scaling relations of $* \mathrm{C}$ (valency 4$)$ and $\mathrm{C}$-containing species with valency $3(* \mathrm{CH}, * \mathrm{COH})$ have peculiar structureindependent offsets. These offsets stem from the analogous bonding of those adsorbates to the adsorption sites, in spite of their dissimilar valency. We show how this result implies that reaction pathways in catalysis involving ${ }^{*} \mathrm{C}$, ${ }^{*} \mathrm{CH}$ and ${ }^{*} \mathrm{COH}$, for instance $\mathrm{CO}_{2}$ electroreduction to $\mathrm{CH}_{4}$, will usually have sizable thermodynamic limits imposed to their optimization.
\end{abstract}




\section{Highlights}

- DFT-based adsorption energies for $\mathrm{C}, \mathrm{CH}_{\mathrm{x}}$ and $\mathrm{COH}$ on various transition metal sites

- The slopes of the scaling lines can be predicted based on electron-counting rules

- Anomalous structure dependence for the offsets of $\mathrm{CH}$ vs $\mathrm{C}$ and $\mathrm{COH}$ vs $\mathrm{C}$

- $\mathrm{COH}$ hydrogenation to produce $\mathrm{C}$ is energy-intensive during $\mathrm{CO}_{2}$ reduction to $\mathrm{CH}_{4}$ 
TOC Figure

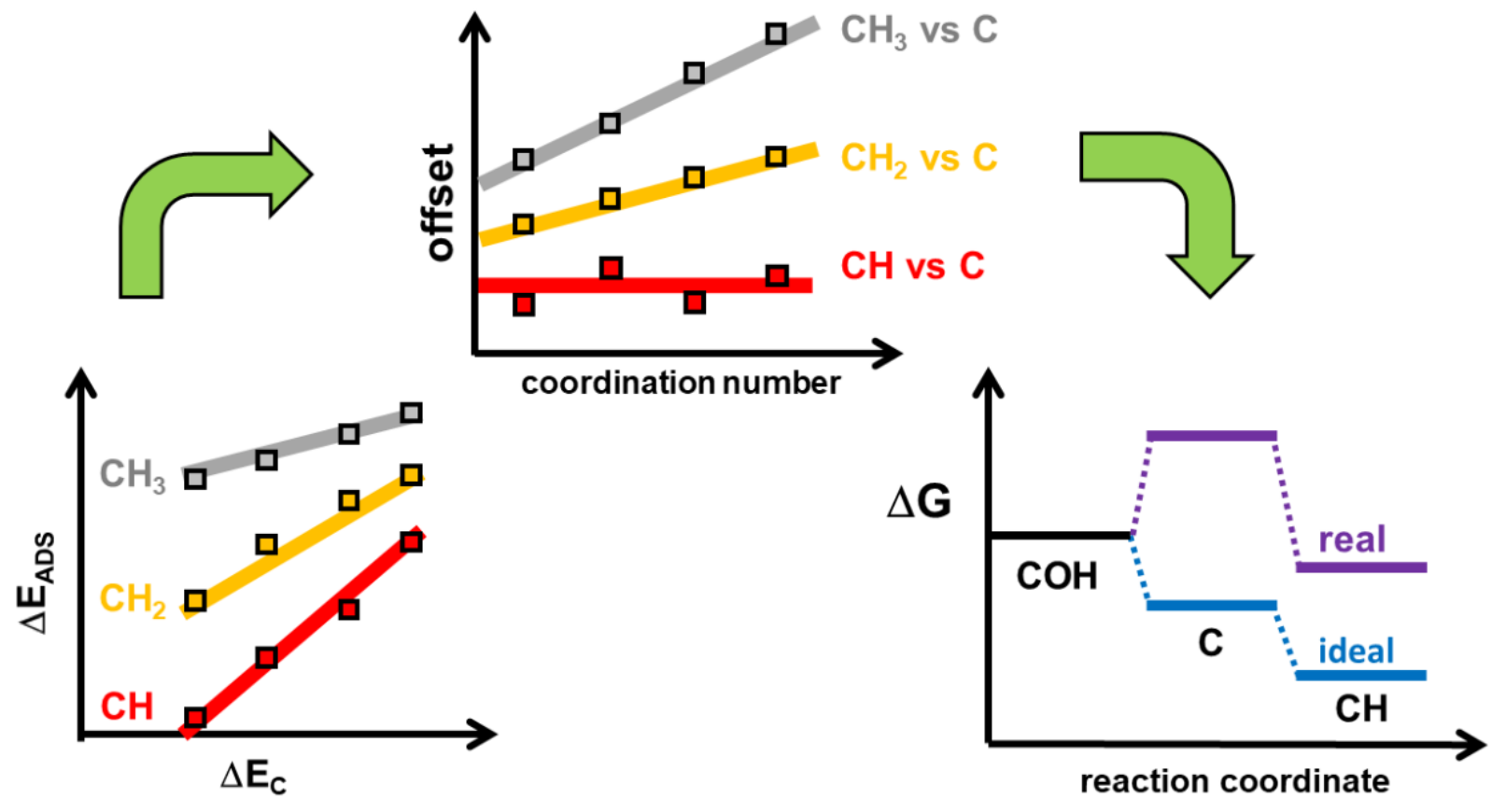




\section{Introduction}

The release of $\mathrm{CO}_{2}$ from anthropogenic sources has been increasing by about $1 \%$ per year in the last few years [1], despite the current efforts towards its reduction, which has led to a great imbalance in the biogeochemical cycle of carbon. While the forced lockdown during the COVID-19 pandemic has led to a temporary reduction in the emissions by early April of an estimated $17 \%$ and a yearly estimated reduction of $4-7 \%$ for 2020 [2], long-term solutions are necessary to mitigate climate change. Among the most centralized emitters of $\mathrm{CO}_{2}$ are the cement industry with around 5-7\% of the global emissions [3] and the fossil-fuel-based electric power production, where the 1000 largest plants produce up to $22 \%$ of the total global fossil fuel $\mathrm{CO}_{2}$ emissions [4]. For these centralized, high-volume emitters, $\mathrm{CO}_{2}$ capture and conversion in electrolyzers is a realistic alternative [5-8]. Furthermore, being able to use renewable energies directly to electrochemically reduce carbon dioxide selectively to valuable fuels and commodities would allow for an efficient carbon recycling scheme [9]. $\mathrm{CO}_{2}$ electroreduction is extremely sensitive to the employed catalyst [10-12] as well as the solvent and the electrolyte used $[13,14]$, which makes the discovery and optimization of catalysts a formidable task $[15,16]$.

An approach to help streamline the search for catalysts is the usage of screening routines based on adsorption-energy scaling relations [17-22]. These relations connect the adsorption energies of two adsorbates $A$ and $B$ on facet $i$ as follow [23,24]:

$\Delta E_{A}^{i}=m \cdot \Delta E_{B}^{i}+b^{i}$

where the slope $m$ is nearly constant for all facets and the y-axis intercept $b^{i}$, hereon referred to as the offset, depends on the geometric structure of the adsorption sites [23,24] .

The slope of the scaling line is typically positive, dimensionless, relatively independent of the simulation method employed and can be assessed by simple electron counting rules [23,25]: $m=N_{A} / N_{B}$, where $N_{A}$ and $N_{B}$ are the number of valence electrons that A and B miss to fulfill the octet rule. For example, the ${ }^{*} \mathrm{CH}$ vs ${ }^{*} \mathrm{C}$ (we follow here the convention $\mathrm{y}$ vs $\mathrm{x}$ ) scaling relation is predicted to have an slope of $3 / 4$, as $* \mathrm{C}$ lacks 4 valence electrons to reach the octet and the carbon atom in $* \mathrm{CH}$ lacks 3 . Likewise, the scaling relation of $* \mathrm{CH}_{2}$ vs $* \mathrm{C}$ should have an inclination of $1 / 2$, and that of $* \mathrm{CH}_{3}$ vs $* \mathrm{C}$ should be $1 / 4$. While this is generally true [23], it is worth noting that phenomena such as the increasing covalent interaction between surface sites and adsorbates can induce departures from the predicted values [26], and usually reduce the 
slope. Besides, negative slopes have also been observed when low-electronegativity species such as * B (adsorbed boron) are scaled with high-electronegativity species such as * $\mathrm{N}$ [27].

The offset has units of energy and is related to the absolute adsorption strength. Thus, it needs to be calculated using e.g. first-principles methods and explicitly depends on the functional and basis sets used. Scaling relations exist on different materials [28,29] and sites including terraces, steps, kinks and akin undercoordinated surface sites [24,30]. When comparing the offsets across different facets for adsorbed oxygen and oxygenates $(* \mathrm{O}, * \mathrm{OH}, * \mathrm{OOH}$ and $* \mathrm{OCH}_{3}$ ), it was observed that they are linearly correlated with the coordination number of the sites, as long as the slope is not 1 [24]. This means that the absolute adsorption energies for lowcoordinated sites can, in principle, be predicted using comparatively simple calculations on highsymmetry facets such as the (111) if the coordination number of the active sites is known. On the other hand, when the slope is unity, the offset is surface independent and can be easily approximated from gas-phase calculations and/or experiments [24,31].

Adsorption-energy scaling relations among ${ }^{*} \mathrm{C}_{\mathrm{x}} \mathrm{H}_{\mathrm{y}}$ species are well known [23,28,32]. Besides, the scaling relation between $* \mathrm{CO}$ and $* \mathrm{CHO}$ has received considerable attention in the literature [33-36] and its breakage is considered essential [16,17] to improve the catalytic processes in which it takes place. However, the structural sensitivity of scaling relations among carbon-based adsorbates remains largely unexplored. Knowledge of that is necessary for the development of swift yet accurate screening routines for $\mathrm{CO}_{2}$ reduction and several other reactions. In this work, we provide the scaling relations of various carbon-containing adsorbates $\left(* \mathrm{C}, * \mathrm{CH},{ }^{*} \mathrm{CH}_{2}, * \mathrm{CH}_{3}, * \mathrm{COH}\right)$ on nine transition metals and five adsorption sites with different coordination numbers. We found a peculiar behavior of the offset of the ${ }^{*} \mathrm{CH}$ vs $* \mathrm{C}$ and $* \mathrm{COH}$ vs *C scaling relations, which would only be expected for pairs of adsorbates with unity slopes. Finally, we discuss the reaches of these results in the light of electrocatalytic $\mathrm{CO}_{2}$ reduction.

\section{Computational details}

The DFT calculations were performed with the VASP code [37], using the projector augmentedwave method to describe ion-electron interactions [38], and the Perdew-Burke-Ernzerhof (PBE) exchange-correlation functional [39]. Geometry optimizations were carried out with a planewave cutoff of $450 \mathrm{eV}$ and the conjugate gradient method. We studied the surfaces of $\mathrm{Cu}, \mathrm{Ag}$, 
$\mathrm{Au}, \mathrm{Ni}, \mathrm{Pd}, \mathrm{Pt}, \mathrm{Co}, \mathrm{Rh}$ and Ir. All metals were simulated in their fcc phase. The tests in section S3 show the reliability of this approximation for Co. Previous works showed that although including spin polarization affects the actual adsorption energies for $\mathrm{Co}$ and $\mathrm{Ni}$, the changes in the parameters of the scaling relations are negligible [35], which is corroborated in section S3. Thus, as a first approximation, we only provide here results for spin-restricted calculations on Co and Ni slabs.

In view of their unsaturation, $* \mathrm{C}, * \mathrm{CH}$ and $* \mathrm{COH}$ usually bind to three or four surface atoms. Therefore, we selected for this study surfaces containing threefold or fourfold hollow sites. In brief, we used $(2 \times 2)(111)$ slabs with 4 layers, $(3 \times 2)(100)$ slabs with 4 layers, $(2 \times 2)$ (110) slabs with 5 layers, $(4 \times 3)$ (100) slabs with 4 layers and 4 metal adatoms (denoted 4AD@100), (3×3) (111) slabs with 4 layers and 3 metal adatoms (denoted 3AD@111), see schematics in Figure 1. All metal atoms in the two topmost layers of the slabs, the metal adatoms, and the adsorbates were allowed to move in all directions until the maximal force on any atom was below $0.05 \mathrm{eV} \AA^{-1}$. The tests done in section S2 show the convergence of the calculations in regard to this cutoff criterion and indicate that the convergence criteria used here are adequate. The atoms in the bottommost layers were set at the optimized bulk distances and made immobile during the simulations. In all cases, the unit cells were large enough in the surface plane to avoid lateral interactions between adsorbates, see Figure 1 and Figure S1 in the Supporting Information (SI). At least $12 \AA$ of vacuum were added in the vertical direction between periodically repeated images and dipole moment corrections were considered during the geometry optimizations to correct the total electronic energies from spurious electrostatic interactions between equivalent periodic slabs. The Methfessel-Paxton method [40] was used to smear the Fermi level with $\mathrm{kBT}_{\mathrm{B}}=0.2 \mathrm{eV}$, and all energies were extrapolated to $0 \mathrm{~K}$. The k-point samplings used were $6 \times 6 \times 1$ for (111) slabs, $6 \times 8 \times 1$ for (100) slabs, $5 \times 4 \times 1$ for (110) slabs, $3 \times 4 \times 1$ for 4AD@100, and (4×4×1) for 3AD@111.

The adsorption energies of species $w$ were calculated as: $\Delta E_{w}=E_{*_{w}}-E_{*}-E_{w}$, with $* w=$ $* \mathrm{C}, * \mathrm{CH}, * \mathrm{CH}_{2},{ }^{*} \mathrm{CH}_{3}, * \mathrm{COH}$; and $w=\mathrm{C}(\mathrm{g}), \mathrm{CH}(\mathrm{g}), \mathrm{CH}_{2}(\mathrm{~g}), \mathrm{CH}_{3}(\mathrm{~g}), \mathrm{COH}(\mathrm{g})$. The total energies of the gas-phase species were calculated in cubic boxes of $15 \AA \times 15 \AA \times 15 \AA$, with $\mathrm{k}_{\mathrm{B}} \mathrm{T}=0.001 \mathrm{eV}$, and sampling only the $\Gamma$-point in spin unrestricted calculations. The resulting magnetic moments of $\mathrm{C}(\mathrm{g}), \mathrm{CH}(\mathrm{g}), \mathrm{CH}_{2}(\mathrm{~g}), \mathrm{CH}_{3}(\mathrm{~g}), \mathrm{COH}(\mathrm{g})$ are $4,1,2,1$, and 1. The adsorption 
energies of $* \mathrm{COH}$ were adapted from previous works [35], except for those on 3AD@111 sites, which were calculated in this work. The free energies were approximated as: $G \approx E+Z P E-T S+E_{\text {solvation }}$. $E$ is the total energy calculated with DFT; ZPE is the zero-point energy calculated with DFT using the harmonic oscillator approximation, $T=298.15 \mathrm{~K}, S$ is the total entropy for gas-phase species and the vibrational entropy for adsorbates; and $E_{\text {solvation }}$ is the stabilization granted by adsorbate-water interactions, taken from previous works [41], see further details in section S6 and specific values in Table S10. The energetics of proton-electron pairs was calculated with the computational hydrogen electrode [42] and the total energy of $\mathrm{CO}_{2}$ corrected using the method in ref. [43].

a. (111), cn = 9

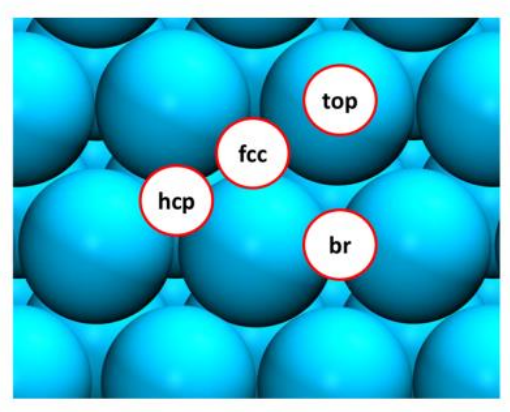

d. 4AD @ (100), cn=6

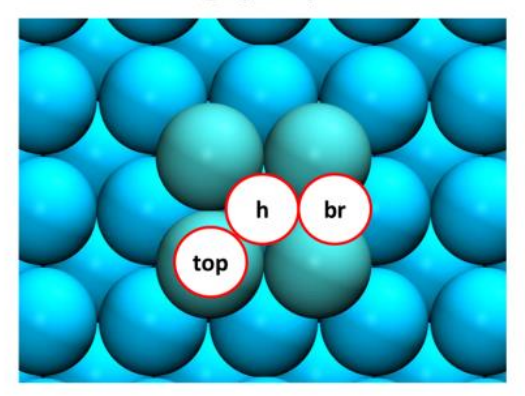

b. $(100), c n=8$

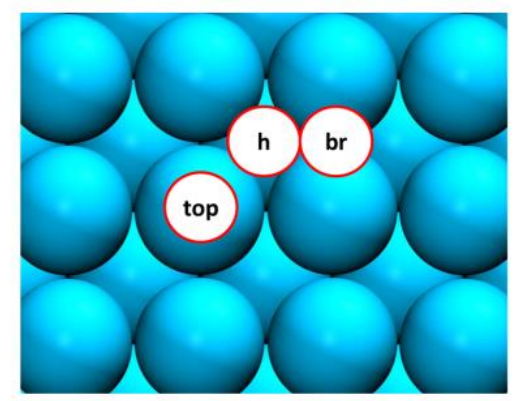

e. 3AD @ (111), cn = 5

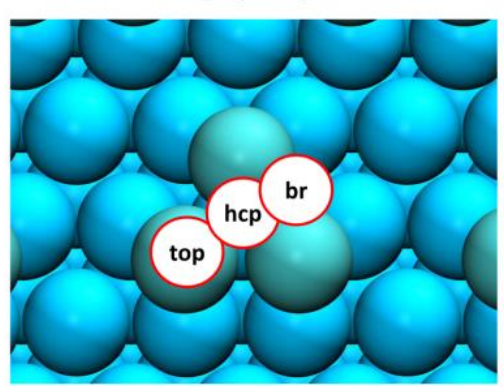

Figure 1. Structures of the adsorption sites under study. a) $\operatorname{Pt}(111)$, b) $\operatorname{Pt}(100)$, c) $\operatorname{Pt}(110)$, d) 4AD@Pt(100), e) 3AD@Pt(111). The adsorption sites where adsorption was inspected for each adsorbate are marked as follows: fcc threefold hollow site (fcc), hcp threefold hollow site (hcp), fourfold hollow sites (h), atop site (top), bridge site (br), long bridge on the $\operatorname{Pt}(110)$ site $\left(\mathrm{br}_{2}\right)$. The adsorption site preferences with respect to the adsorbate and the surface type can be found in Tables S3-S8 in the SI. Figure S1 shows the unit cells used in the calculations. 


\section{Results and discussion}

\subsection{Scaling relations for $\mathrm{CH}_{\mathrm{x}}$ species $(\mathrm{x}=1,2,3)$}

The five adsorption sites investigated together with their representative coordination number can be found in Figure 1. The adsorption site preferences can be found in Tables S3-S8 in the SI for each species, metal and coordination number. We observed that $* \mathrm{C}, * \mathrm{CH}$ and $* \mathrm{COH}$ prefer to adsorb at three- or fourfold hollow sites in the vast majority of cases, whereas ${ }^{*} \mathrm{CH}_{2}$ tends to adsorb at bridge sites, but also adsorbs in some cases on hollow sites. ${ }^{*} \mathrm{CH}_{3}$ adsorbs on bridge and top sites.

The scaling relations of $* \mathrm{CH}_{\mathrm{x}}$ vs $* \mathrm{C}$, established using the most stable adsorption sites for every adsorbate, appear in Figure 2. For the adsorption of $* \mathrm{CH}$ vs $* \mathrm{C}$ we observe an average slope of 0.77 , which is close to the expected value of $3 / 4$ and in agreement with the values in previous publications [23]. For the ${ }^{*} \mathrm{CH}_{2}$ vs $* \mathrm{C}$ scaling we observe an average slope of 0.50 which, again, matches the prediction of $1 / 2$ based on electron-counting rules and compares favorably to previous results [23] . Lastly, the ${ }^{*} \mathrm{CH}_{3}$ vs $* \mathrm{C}$ scaling shows an average slope of 0.25 , which also matches the prediction of $1 / 4$ and previous results [23]. In conclusion, as in the case of oxygenates [24], the slope is not structure sensitive and can, as a first approximation, be safely estimated from electron-counting rules. 

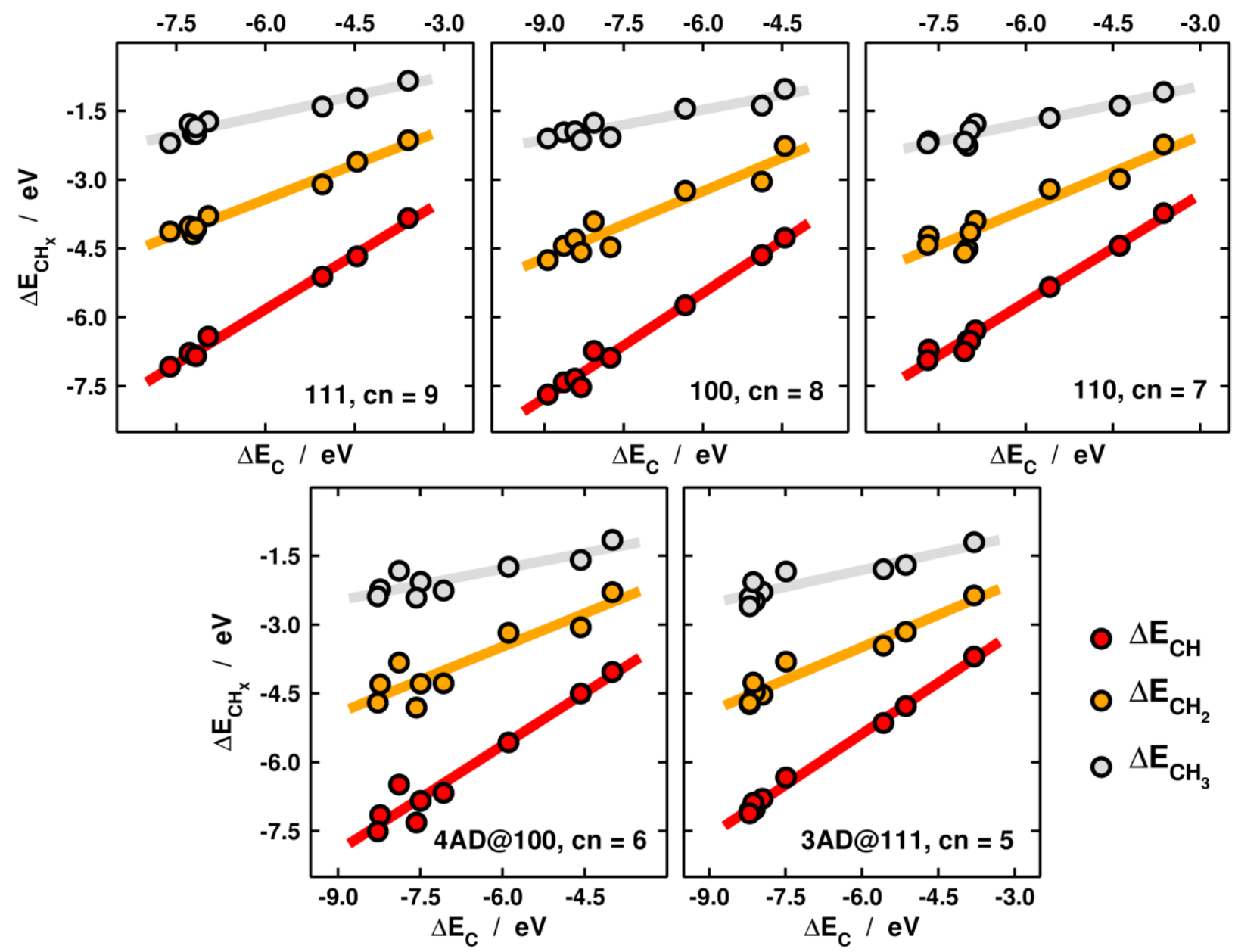

- $\Delta \mathrm{E}_{\mathrm{CH}}$
o $\Delta \mathrm{E}_{\mathrm{CH}_{2}}$
ㅇ $\Delta \mathrm{E}_{\mathrm{CH}_{3}}$

Figure 2. Adsorption-energy scaling relations between the adsorption energies of ${ }^{*} \mathrm{C}$ and ${ }^{*} \mathrm{CH}$ (red), ${ }^{*} \mathrm{CH}_{2}$ (orange), and $* \mathrm{CH}_{3}$ (gray) on the five surface sites under study, for nine transition metals. The facet and its representative coordination number $(c n)$ is provided in each panel. The parameters of the linear fits can be found in Table S8.

\subsection{The offsets of the ${ }^{*} \mathrm{CH}_{\mathrm{x}}$ vs $* \mathrm{C}$ scaling relations}

We collected the offsets of all scaling relations displayed in Figure 2 and plotted them as a function of the coordination number of the adsorption sites in Figure 3. We observe that the offsets for ${ }^{*} \mathrm{CH}_{2}$ vs $* \mathrm{C}$ and ${ }^{*} \mathrm{CH}_{3}$ vs $* \mathrm{C}$ exhibit a linear growth with increasing coordination number, in line with previous observations for oxygenates vs *O [24]. As shown in section S5, the ratio of the slopes for ${ }^{*} \mathrm{CH}_{3}$ vs $* \mathrm{C}$ and ${ }^{*} \mathrm{CH}_{2}$ vs $* \mathrm{C}$ in Figure 3 is connected to the adsorption energies of ${ }^{*} \mathrm{CH}_{3}$ and ${ }^{*} \mathrm{CH}_{2}$ by means of Equation 2, where $\alpha_{C H_{x} \text { vs } C}$ is the slope in Figure 3,i and $j$ are two different surface facets (see Figure 1) with coordination numbers $c n^{i}$ and $c n^{j}$, and $M$ is a given metal. 


$$
\frac{\alpha_{\mathrm{CH}_{3} \text { vs } C}}{\alpha_{\mathrm{CH}_{2} \text { vs } C}} \approx\left(\frac{\Delta E_{\mathrm{CH}_{3}}^{i, M}-\Delta E_{C H_{3}}^{j, M}}{\Delta E_{C H_{2}}^{i, M}-\Delta E_{C H_{2}}^{j, M}}\right)
$$

According to Equation 2, the relatively larger slope observed in Figure 3 for the ${ }^{*} \mathrm{CH}_{3}$ vs ${ }^{*} \mathrm{C}$ scaling relation with respect to ${ }^{*} \mathrm{CH}_{2}$ vs $* \mathrm{C}$ stems from the fact that $* \mathrm{CH}_{3}$ adsorption energies generally become more negative than those of $* \mathrm{CH}_{2}$ when the coordination number of the active sites is decreased, see further details in section S5.

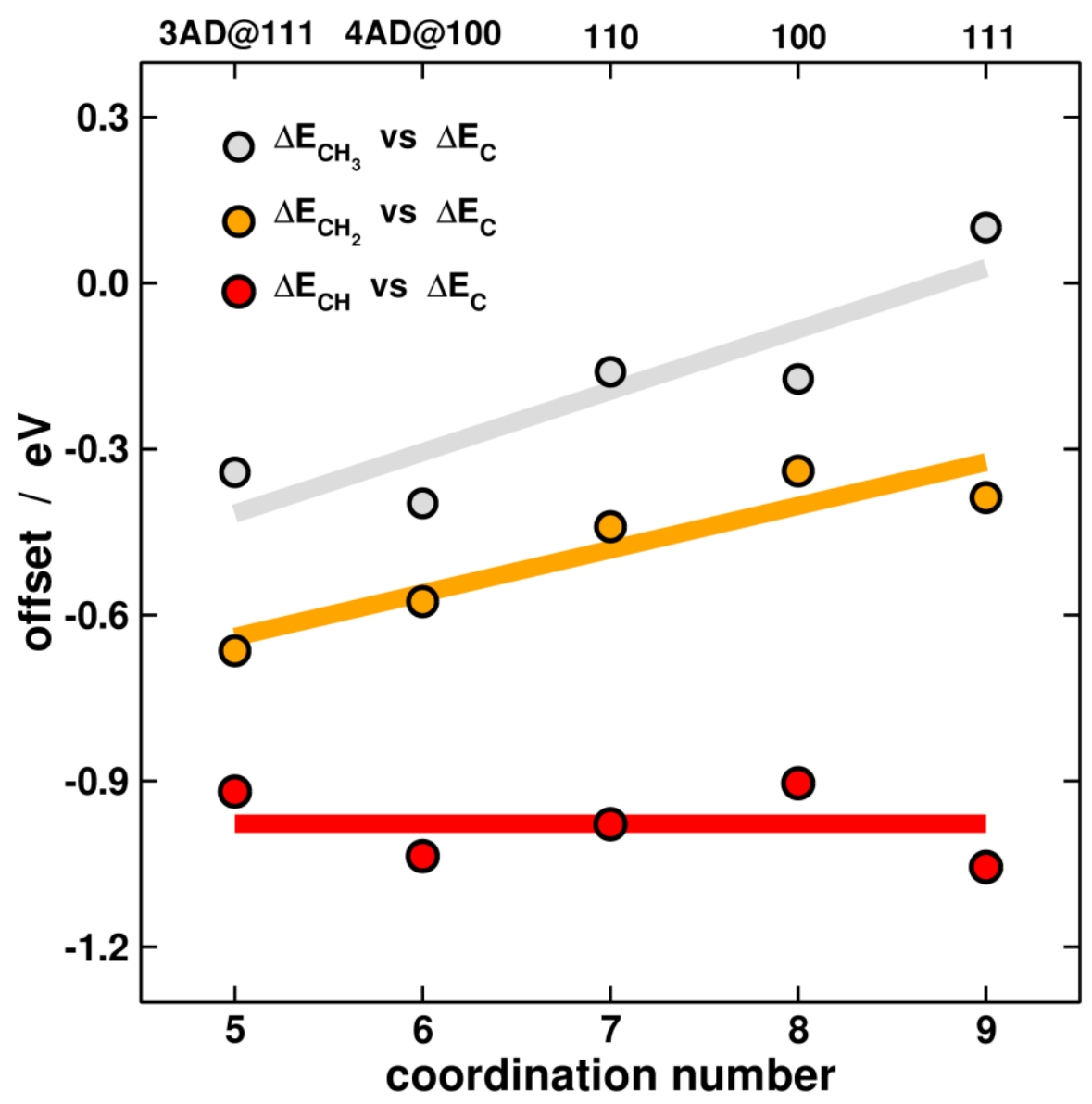

Figure 3. Offsets of the adsorption-energy scaling relations between ${ }^{*} \mathrm{C}$ and ${ }^{*} \mathrm{CH}$ (red), ${ }^{*} \mathrm{CH}_{2}$ (orange), and ${ }^{*} \mathrm{CH}_{3}$ (gray) as a function of the coordination number of the adsorption sites. The parameters of the linear fits can be found in the SI, Table S8.

In contrast, the offset for $* \mathrm{CH}$ vs $* \mathrm{C}$ is essentially constant for all studied surface sites at an average value of $-0.98 \mathrm{eV}$, with a mean absolute error (MAE) of $0.07 \mathrm{eV}$. In turn, this implies 
that the adsorption energy difference between ${ }^{*} \mathrm{C}$ and $* \mathrm{CH}$ adsorption is nearly constant for all facets of a given metal. The constant offset can be rationalized as follows: first, on every facet and metal $* \mathrm{C}$ and $* \mathrm{CH}$ adsorb always at the same sites, namely hollow sites, unlike ${ }^{*} \mathrm{CH}_{2}$ and ${ }^{*} \mathrm{CH}_{3}$ (see Tables S3-S8). Second, the bonding of $* \mathrm{C}$ is presumably similar to that of $* \mathrm{CH}$ because it is difficult for $* \mathrm{C}$ to make four $\sigma$ bonds to the surface, in view of its hybridization and the spatial orientation of its orbitals [23]. Indeed, a ${ }^{*} \mathrm{C}$ atom with four bonds has $\mathrm{sp}^{3}$ hybridization and, because of that, should be spatially organized in a tetrahedral fashion. This is not possible on a flat, 2D adsorption site, where all surface atoms are in the same plane. We note as well that some surface sites in Figure 1 are threefold, such that, following effective medium theory $[23,44] * \mathrm{C}$ can only position itself at a distance from the surface that offers an electron density equivalent to that a stable gas-phase counterpart, namely, $\mathrm{CH}_{4}$.

Accordingly, the constant energetic separation could be a general phenomenon noticeable in the scaling relations between $* \mathrm{C}$ and $\mathrm{C}$-containing species with a valency of 3 . To evaluate this hypothesis, we calculated the adsorption energies of $* \mathrm{COH}$, the carbon atom of which lacks three electrons to fulfill the octet rule, similar to ${ }^{*} \mathrm{CH}$ (see Tables S3-S8 for the adsorption energies, and Table S9 for the parameters of the linear fits). In the light of the theory of scaling relations [19-21,23,24], the scaling relation of $* \mathrm{COH}$ vs $* \mathrm{CH}$ should have a unity slope and a single offset for all facets, in view of their identical valency. Besides, that of $* \mathrm{COH}$ vs $* \mathrm{C}$ should have a slope of 0.75 and a single offset, as well. This is indeed what we observe in Figure 4, where the slopes are $0.75\left({ }^{*} \mathrm{CH}\right.$ vs $\left.* \mathrm{C}\right), 0.74\left({ }^{*} \mathrm{COH}\right.$ vs $\left.* \mathrm{C}\right)$, and $0.99\left({ }^{*} \mathrm{COH}\right.$ vs $\left.* \mathrm{CH}\right)$, and all data can be described with a single offset per pair of adsorbates with MAEs of 0.19, 0.26 and $0.16 \mathrm{eV}$ in wide a range of $\mathrm{C}$ adsorption energies $(>5 \mathrm{eV})$. 


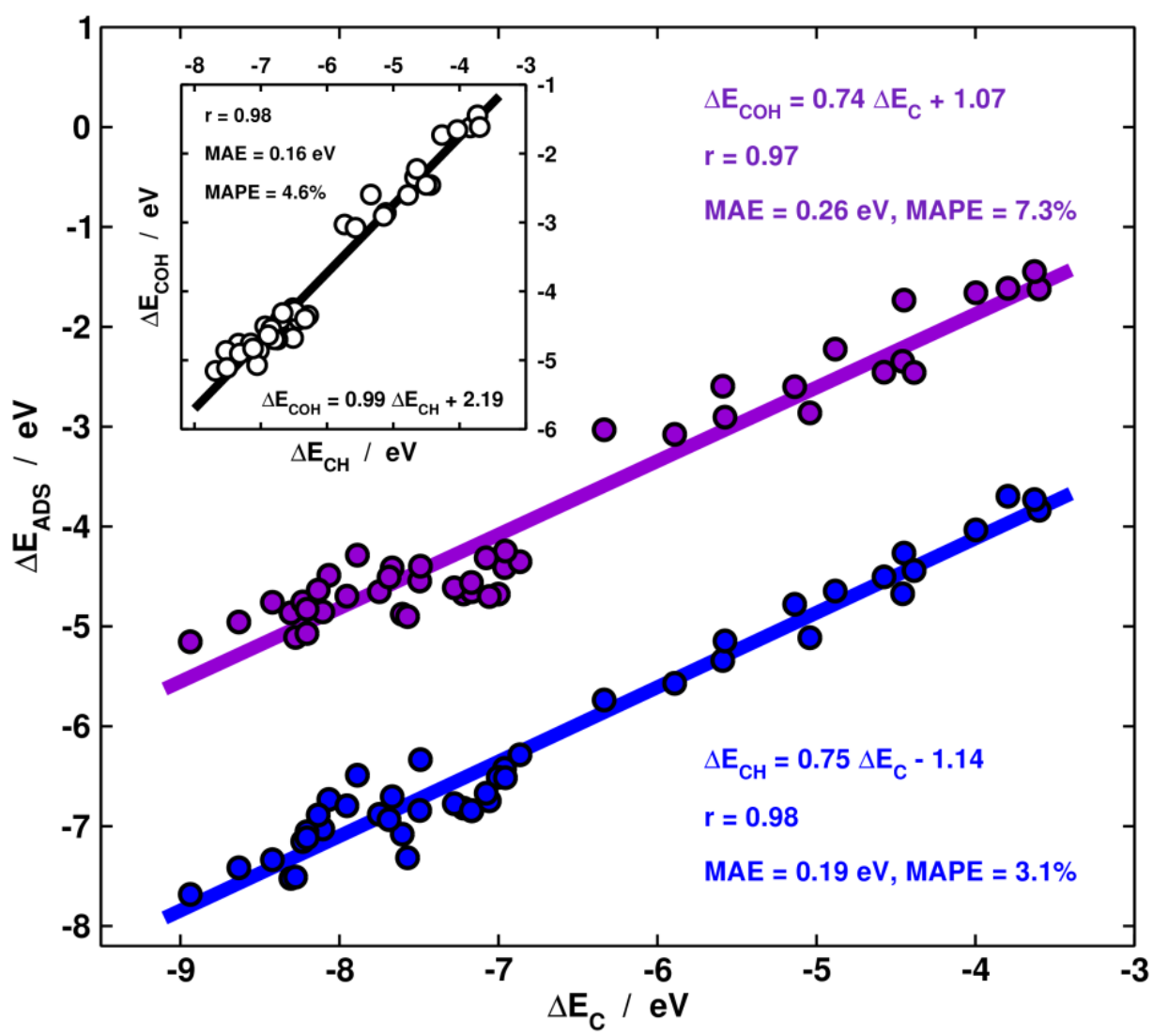

Figure 4. Adsorption-energy scaling relations between ${ }^{*} \mathrm{C}$ (violet), ${ }^{*} \mathrm{CH}$ (blue), and ${ }^{*} \mathrm{COH}$ (cyan) on five surface sites for nine transition metals. Inset: Scaling relation for $* \mathrm{COH}$ vs ${ }^{*} \mathrm{CH}$. The linear fits and the correlation coefficients ( $\mathrm{r}$ ) are provided in each case. The respective MAEs between the lines and the calculated datapoints are $0.19,0.26$ and $0.16 \mathrm{eV}$ for $* \mathrm{CH}$ vs $\mathrm{C},{ }^{*} \mathrm{COH}$ vs $* \mathrm{C}$, and ${ }^{*} \mathrm{COH}$ vs $* \mathrm{CH}$.

\subsection{Possible implications for $\mathrm{CO}_{2}$ electroreduction}

For the past decade, adsorption-energy scaling relations have been widely applied for the computational discovery and optimization of (electro)catalysts $[9,16,20,21]$. While initially it was observed that they simplify screening routines for the design of catalytic materials, it was later noted that they also impose thermodynamic limitations to efficiency of catalysts. This led to the notion of "intrinsic", scaling-based overpotential in computational electrocatalysis $[19,45,46]$. With the scaling between ${ }^{*} \mathrm{C},{ }^{*} \mathrm{COH}$ and ${ }^{*} \mathrm{CH}$ in mind, we noted that those three adsorbates have repeatedly been listed as intermediates of the $\mathrm{CO}_{2}$ reduction reaction $\left(\mathrm{CO}_{2} \mathrm{RR}\right)$ to $\mathrm{CH}_{4}[35,36,41,47-50] . * \mathrm{COH}$ can be formed from $* \mathrm{CO}$ hydrogenation, and the following two subsequent steps can follow: 
${ }^{*} \mathrm{COH}+\mathrm{H}^{+}+e^{-} \rightarrow{ }^{*} \mathrm{C}+\mathrm{H}_{2} \mathrm{O}$

${ }^{*} \mathrm{C}+\mathrm{H}^{+}+e^{-} \rightarrow{ }^{*} \mathrm{CH}+\mathrm{H}_{2} \mathrm{O}$

The addition of Equations 3 and 4 shows that $* \mathrm{COH}$ and $* \mathrm{CH}$ are separated by two electrons $\left({ }^{*} \mathrm{COH}+2 \mathrm{H}^{+}+2 e^{-} \rightarrow{ }^{*} \mathrm{CH}+\mathrm{H}_{2} \mathrm{O}\right)$, and Figure 4 shows that they scale with a slope close to 1 . The equilibrium potential of the $\mathrm{CO}_{2} \mathrm{RR}_{\text {to }} \mathrm{CH}_{4}\left(\mathrm{CO}_{2}+8 \mathrm{H}^{+}+8 e^{-} \rightarrow \mathrm{CH}_{4}+2 \mathrm{H}_{2} \mathrm{O}\right)$ is $0.17 \mathrm{~V}$ and the free energy of the reaction is $-1.36 \mathrm{eV}$. In this order of ideas, in an ideal $\mathrm{CO}_{2} \mathrm{RR}$ catalyst each proton-electron pair is transferred involving reaction energies of $-0.17 \mathrm{eV}$. Therefore, ${ }^{*} \mathrm{COH}$ and $* \mathrm{CH}$ should ideally be separated by $0.34 \mathrm{eV}$, and ${ }^{*} \mathrm{C}$ should be exactly in between, at $0.17 \mathrm{eV}$.

In Figure 5 we show that the calculated separation between ${ }^{*} \mathrm{CH}$ and ${ }^{*} \mathrm{COH}$ is $0.06 \mathrm{eV}$ (note that it is $2.19 \mathrm{eV}$ in Figure 4, because the gas-phase reference is different, see the Methods section and section S5), so that on average there is a mismatch of $0.28 \mathrm{eV}$ (see Figure S3 of the SI for details about adsorption energies of ${ }^{*} \mathrm{COH},{ }^{*} \mathrm{C},{ }^{*} \mathrm{CH}$ intermediates on the considered surfaces and deviations with respect to average values). While this could lead to a scaling-based overpotential of $\sim 0.14 \mathrm{~V}[19,47]$, Figure 5 suggests that the location of $* \mathrm{C}$ with respect to $* \mathrm{COH}$ can lead to considerably larger overpotentials. A second version of Figure 5, containing the standard deviations for the individual intermediate energies, can be found in the SI (Figure S4). Indeed, ${ }^{*} \mathrm{COH}$ hydrogenation to produce ${ }^{*} \mathrm{C}$ (Equation 3 ) is generally an endothermic process and may require significant overpotentials.

This is important to note, as it is usually considered that * $\mathrm{CO}$ hydrogenation to either ${ }^{*} \mathrm{CHO}$ or ${ }^{*} \mathrm{COH}$ is the potential-limiting step of $\mathrm{CO}_{2} \mathrm{RR}$ to $\mathrm{CH}_{4}[16,33-36,41,47-50]$ Once that step is optimized, probably the next target would be ${ }^{*} \mathrm{COH}$ hydrogenation for materials in which: (i) ${ }^{*} \mathrm{COH}$ is more readily formed than ${ }^{*} \mathrm{CHO}$, which depends on the metal site, its coordination, and the adsorbate-solvent interactions [35]. ii) ${ }^{*} \mathrm{C}$ is more stable than ${ }^{*} \mathrm{CHOH}$. Optimizing ${ }^{*} \mathrm{COH}$ hydrogenation might prove challenging, as ${ }^{*} \mathrm{C}$ and ${ }^{*} \mathrm{COH}$ are shown here to bind similarly to transition metal surfaces.

We note that we have focused here on the steps following the formation of $* \mathrm{COH}$, due to the general interest in higher $\mathrm{C}_{1}$ reduction products, such as methane. A comprehensive analysis of $\mathrm{CO}_{2}$ reduction to $\mathrm{CO}$ can be found elsewhere [51]. Note in passing that in Figure 5 we averaged all values in two different ways, namely by facet (main panel) and by element (see the 
inset), so as to condense all of the data and ease their visualization. Combining the results in the main panel and the inset, we conclude that $* \mathrm{COH}$ hydrogenation to $* \mathrm{C}$ will be particularly difficult for (111) surfaces of $\mathrm{Cu}$ and noble metals such as $\mathrm{Ag}, \mathrm{Au}$, and $\mathrm{Pt}$, with and without step edges. On the other hand, ${ }^{*} \mathrm{COH}$ hydrogenation to ${ }^{*} \mathrm{C}$ seems particularly favorable at (100) terraces, which warrants future analysis: on the one hand, an easy formation of ${ }^{*} \mathrm{C}$ is desirable for efficient $\mathrm{CO}_{2} \mathrm{RR}$ to e.g. $\mathrm{CH}_{4}$. On the other hand, the formation of ${ }^{*} \mathrm{C}$ combined with low surface diffusion barriers might lead to coking and, hence, electrode deactivation.

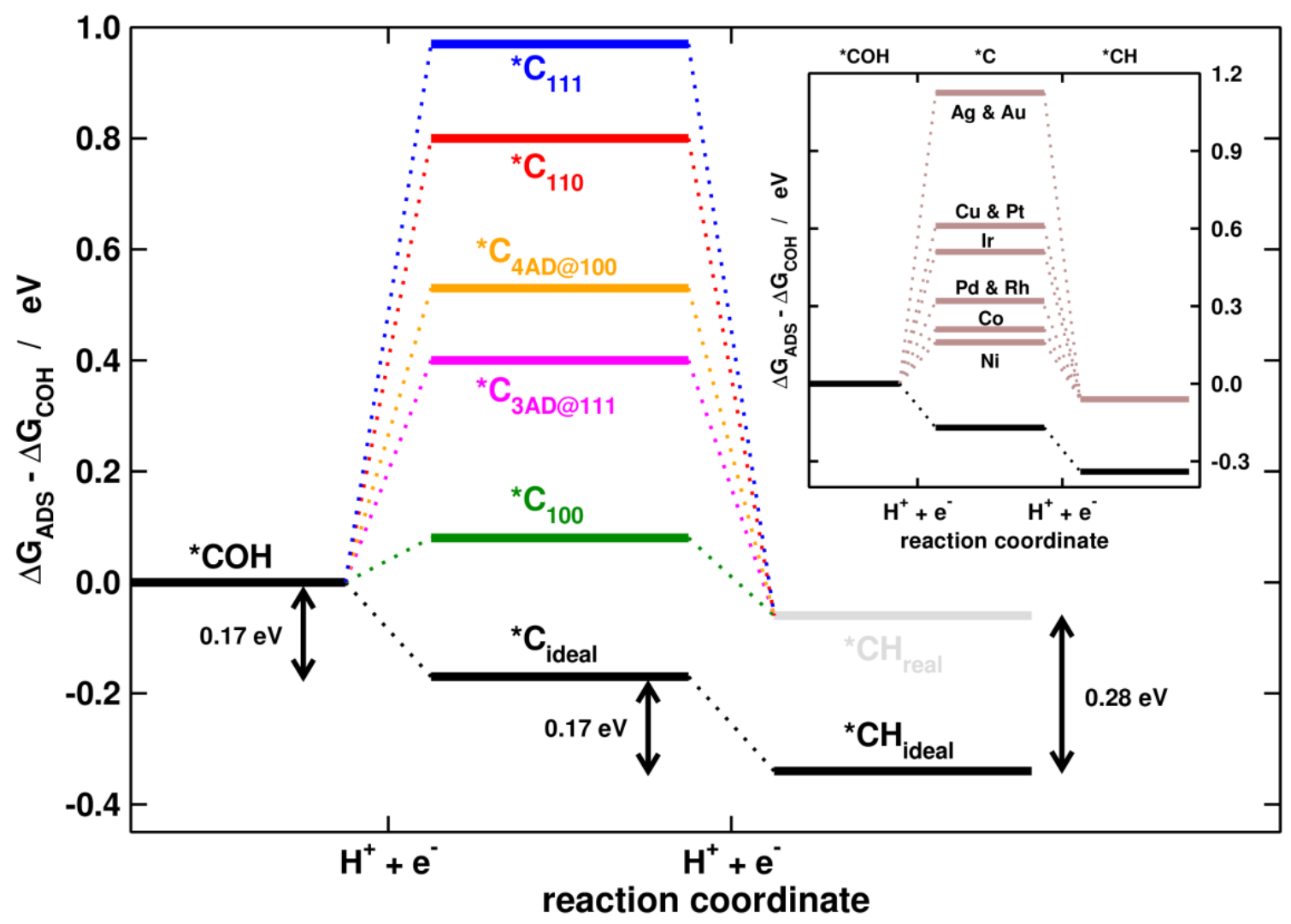

Figure 5. Reaction coordinate for the sequential hydrogenation of $* \mathrm{COH}$ to $* \mathrm{C}$ and $* \mathrm{CH}$ on late transition metal surfaces. In the $\mathrm{y}$-axis the free energies are presented with respect to ${ }^{*} \mathrm{COH}$. The values in black labelled as "ideal" for * $\mathrm{CH}$ and $* \mathrm{COH}$ come from thermodynamic considerations, see the text. The data in colors labelled as "real" or labelled with facets are averages from Tables S3-S8 duly converted into free energies (see section S6). Inset: Free energies with respect to $* \mathrm{COH}$, averaged per metal.

\section{Conclusions}


From our simulations it becomes apparent that the adsorption-energy scaling relations of $* \mathrm{CH}$ vs ${ }^{*} \mathrm{C}$ and ${ }^{*} \mathrm{COH}$ vs ${ }^{*} \mathrm{C}$ on transition metal surfaces show an unexpected structural independence. In particular, the offset of such scaling relations is relatively constant across coordination numbers, which so far had only been observed for adsorbates with equal valency, such as ${ }^{*} \mathrm{OH}$ and $* \mathrm{OOH}$. This leads to three main conclusions:

- Firstly, the adsorbate-surface bonding of ${ }^{*} \mathrm{C},{ }^{*} \mathrm{COH}$ and ${ }^{*} \mathrm{CH}$ is similar on an electronic scale. Further research into finding an understanding at the orbital level of the ${ }^{*} \mathrm{C},{ }^{*} \mathrm{COH}$ and ${ }^{*} \mathrm{CH}$ bonding on transition metal surfaces is warranted. This could be achieved by analyzing the density of states, via charge-density plots, using descriptors such as the electron-localization function (ELF) and the (integrated) crystal orbital overlap/Hamiltonian populations (COOP and COHP), and by carrying out an energy-decomposition analysis and/or a principal-component analysis [27,52-55].

- Secondly, the adsorption energy of ${ }^{*} \mathrm{C}$ is not independent of those of ${ }^{*} \mathrm{CH}$ and ${ }^{*} \mathrm{COH}$, which suggests that that there will be a scaling-relation-based limit to the efficiency of electrocatalysts in reactions that involve those three intermediates. This merits serious consideration when designing new catalysts for reactions pertaining to the carbon cycle.

- A particular case of interest is the $\mathrm{CO}_{2} \mathrm{RR}$ to $\mathrm{CH}_{4}$, for which ${ }^{*} \mathrm{COH},{ }^{*} \mathrm{C}$ and ${ }^{*} \mathrm{CH}$ are likely intermediates. Currently the hydrogenation of $* \mathrm{CO}$ to ${ }^{*} \mathrm{CHO}$ or $* \mathrm{COH}$ is thought to be the potential-limiting step, but once this step is optimized, ${ }^{*} \mathrm{COH}$ hydrogenation is likely the next candidate for optimization, which might be complicated in view of the peculiar structural sensitivity of the adsorption-energy scaling relations shown in this paper.

\section{Acknowledgments}

F.C.-V acknowledges funding from Spanish MICIUN RTI2018-095460-B-I00, Ramón y Cajal RYC-2015-18996 and María de Maeztu MDM-2017-0767 grants and partly by Generalitat de Catalunya 2017SGR13. We thank Red Española de Supercomputación (RES) for supercomputing time at SCAYLE (projects QS-2019-3-0018, QS-2019-2-0023, and QCM-2019-10034) and MareNostrum (project QS-2020-1-0012). The use of supercomputing facilities at SURFsara was sponsored by NWO Physical Sciences, with financial support by NWO. The 
authors also thank GENCI resources (Project 609) and PSMN in Lyon for CPU time and assistance, as well as the CPER/SYSPROD project (N²019-AURA-P5B) for financial support.

\section{Competing financial interests}

The authors declare no competing financial interests.

\section{References}

[1] R.B. Jackson, P. Friedlingstein, R.M. Andrew, J.G. Canadell, C. le Quéré, G.P. Peters, Persistent fossil fuel growth threatens the Paris Agreement and planetary health, Environmental Research Letters. 14 (2019) 121001.

[2] C. le Quéré, R.B. Jackson, M.W. Jones, A.J.P. Smith, S. Abernethy, R.M. Andrew, A.J. De-Gol, D.R. Willis, Y. Shan, J.G. Canadell, P. Friedlingstein, F. Creutzig, G.P. Peters, Temporary reduction in daily global $\mathrm{CO}_{2}$ emissions during the COVID-19 forced confinement, Nature Climate Change. 10 (2020) 647-653.

[3] E. Benhelal, G. Zahedi, E. Shamsaei, A. Bahadori, Global strategies and potentials to curb $\mathrm{CO}_{2}$ emissions in cement industry, Journal of Cleaner Production. 51 (2013) 142-161.

[4] J.C. Turnbull, E.D. Keller, M.W. Norris, R.M. Wiltshire, Independent evaluation of point source fossil fuel $\mathrm{CO}_{2}$ emissions to better than $10 \%$, Proceedings of the National Academy of Sciences. 113 (2016) 10287-10291.

[5] F. Studt, M. Behrens, E.L. Kunkes, N. Thomas, S. Zander, A. Tarasov, J. Schumann, E. Frei, J.B. Varley, F. Abild-Pedersen, J.K. Nørskov, R. Schlögl, The Mechanism of $\mathrm{CO}$ and $\mathrm{CO}_{2}$ Hydrogenation to Methanol over Cu-Based Catalyst, ChemCatChem. 7 (2015) 1105-1111.

[6] B. Hu, C. Guild, S.L. Suib, Thermal, electrochemical, and photochemical conversion of $\mathrm{CO}_{2}$ to fuels and value-added products, Journal of $\mathrm{CO}_{2}$ Utilization. 1 (2013) 18-27.

[7] A. Mustafa, B.G. Lougou, Y. Shuai, Z. Wang, H. Tan, Current technology development for $\mathrm{CO}_{2}$ utilization into solar fuels and chemicals: A review, Journal of Energy Chemistry. 49 (2020) 96123.

[8] O.S. Bushuyev, P. de Luna, C.T. Dinh, L. Tao, G. Saur, J. van de Lagemaat, S.O. Kelley, E.H. Sargent, What Should We Make with $\mathrm{CO}_{2}$ and How Can We Make It?, Joule. 2 (2018) 825-832.

[9] Z.W. Seh, J. Kibsgaard, C.F. Dickens, I. Chorkendorff, J.K. Nørskov, T.F. Jaramillo, Combining theory and experiment in 
electrocatalysis: Insights into materials design, Science. 355 (2017).

[10] G.O. Larrazábal, A.J. Martín, J. Pérez-Ramírez, Building Blocks for High Performance in Electrocatalytic $\mathrm{CO}_{2}$ Reduction: Materials, Optimization Strategies, and Device Engineering, The Journal of Physical Chemistry Letters. 8 (2017) 3933-3944.

[11] C. Liu, M.P. Lourenço, S. Hedström, F. Cavalca, O. Diaz-Morales, H.A. Duarte, A. Nilsson, L.G.M. Pettersson, Stability and Effects of Subsurface Oxygen in Oxide-Derived Cu Catalyst for CO2 Reduction, The Journal of Physical Chemistry C. 121 (2017) 25010-25017.

[12] J. Shen, M.J. Kolb, Göttle Adrien J., M.T.M. Koper, DFT Study on the Mechanism of the Electrochemical Reduction of $\mathrm{CO}_{2}$ Catalyzed by Cobalt Porphyrins, The Journal of Physical Chemistry C. 120 (2016) 15714-15721.

[13] B.A. Rosen, A. Salehi-Khojin, M.R. Thorson, W. Zhu, D.T. Whipple, P.J.A. Kenis, R.I. Masel, Ionic Liquid-Mediated Selective Conversion of $\mathrm{CO}_{2}$ to $\mathrm{CO}$ at Low Overpotentials, Science. 334 (2011) 643-644.

[14] A.D. Handoko, H. Chen, Y. Lum, Q. Zhang, B. Anasori, Z.W. Seh, Two-Dimensional Titanium and Molybdenum Carbide MXenes as Electrocatalysts for $\mathrm{CO}_{2}$ Reduction, IScience. 23 (2020).

[15] Z.P. Jovanov, H.A. Hansen, A.S. Varela, P. Malacrida, A.A. Peterson, J.K. Nørskov, I.E.L. Stephens, I. Chorkendorff, Opportunities and challenges in the electrocatalysis of $\mathrm{CO}_{2}$ and $\mathrm{CO}$ reduction using bifunctional surfaces: A theoretical and experimental study of AuCd alloys, Journal of Catalysis. 343 (2016) 215-231.

[16] Y. Li, Q. Sun, Recent Advances in Breaking Scaling Relations for Effective Electrochemical Conversion of $\mathrm{CO}_{2}$, Advanced Energy Materials. 6 (2016) 1600463.

[17] J. Pérez-Ramírez, N. López, Strategies to break linear scaling relationships, Nature Catalysis. 2 (2019).

[18] M. Andersen, S. v. Levchenko, M. Scheffler, K. Reuter, Beyond Scaling Relations for the Description of Catalytic Materials, ACS Catalysis. 9 (2019).

[19] M.T.M. Koper, Thermodynamic theory of multi-electron transfer reactions: Implications for electrocatalysis, Journal of Electroanalytical Chemistry. 660 (2011) 254-260.

[20] M.M. Montemore, J.W. Medlin, Scaling relations between adsorption energies for computational screening and design of catalysts, Catal. Sci. Technol. 4 (2014) 3748-3761.

[21] J. Greeley, Theoretical Heterogeneous Catalysis: Scaling Relationships and Computational Catalyst Design, Annual Review of Chemical and Biomolecular Engineering. 7 (2016) 605-635.

[22] K.S. Exner, Recent Progress in the Development of Screening Methods to Identify Electrode Materials for the Oxygen Evolution Reaction, Advanced Functional Materials. (2020) 2005060. 
[23] F. Abild-Pedersen, J. Greeley, F. Studt, J. Rossmeisl, T.R. Munter, P.G. Moses, E. Skúlason, T. Bligaard, J.K. $\mathrm{N} \backslash \mathrm{o}\{\}$ rskov, Scaling Properties of Adsorption Energies for Hydrogen-Containing Molecules on Transition-Metal Surfaces, Phys. Rev. Lett. 99 (2007) 16105.

[24] F. Calle-Vallejo, D. Loffreda, M.T.M. Koper, P. Sautet, Introducing structural sensitivity into adsorption-energy scaling relations by means of coordination numbers, Nature Chemistry. 7 (2015) 403410.

[25] F. Calle-Vallejo, J.I. Martínez, J.M. García-Lastra, J. Rossmeisl, M.T.M. Koper, Physical and Chemical Nature of the Scaling Relations between Adsorption Energies of Atoms on Metal Surfaces, Physical Review Letters. 108 (2012).

[26] F. Calle-Vallejo, A. Krabbe, J.M. García-Lastra, How covalence breaks adsorption-energy scaling relations and solvation restores them, Chem. Sci. 8 (2017) 124-130.

[27] H.-Y. Su, K. Sun, W.-Q. Wang, Z. Zeng, Calle-Vallejo Federico, W.-X. $\mathrm{Li}$, Establishing and Understanding Adsorption-Energy Scaling Relations with Negative Slopes, The Journal of Physical Chemistry Letters. 7 (2016) 5302-5306.

[28] E.M. Fernández, P.G. Moses, A. Toftelund, H.A. Hansen, J.I. Martínez, F. Abild-Pedersen, J. Kleis, B. Hinnemann, J. Rossmeisl, T. Bligaard, J.K. Nørskov, Scaling Relationships for Adsorption Energies on Transition Metal Oxide, Sulfide, and Nitride Surfaces, Angewandte Chemie International Edition. 47 (2008).

[29] T. Choksi, P. Majumdar, J.P. Greeley, Electrostatic Origins of Linear Scaling Relationships at Bifunctional Metal/Oxide Interfaces: A Case Study of Au Nanoparticles on Doped $\mathrm{MgO}$ Substrates, Angewandte Chemie International Edition. 57 (2018).

[30] L.T. Roling, F. Abild-Pedersen, Structure-Sensitive Scaling Relations: Adsorption Energies from Surface Site Stability, ChemCatChem. 10 (2018) 1643-1650.

[31] Karp Eric M., T.L. Silbaugh, Campbell Charles T, Bond Energies of Molecular Fragments to Metal Surfaces Track Their Bond Energies to H Atoms, Journal of the American Chemical Society. 136 (2014) 4137-4140.

[32] G. Jones, F. Studt, F. Abild-Pedersen, J.K. Nørskov, T. Bligaard, Scaling relationships for adsorption energies of $\mathrm{C} 2$ hydrocarbons on transition metal surfaces, Chemical Engineering Science. 66 (2011).

[33] A.A. Peterson, J.K. Nørskov, Activity Descriptors for $\mathrm{CO}_{2}$ Electroreduction to Methane on Transition-Metal Catalysts, The Journal of Physical Chemistry Letters. 3 (2012) 251-258.

[34] H.A. Hansen, C. Shi, A.C. Lausche, A.A. Peterson, J.K. Nørskov, Bifunctional alloys for the electroreduction of $\mathrm{CO}_{2}$ and $\mathrm{CO}$, Phys. Chem. Chem. Phys. 18 (2016) 9194-9201. 
[35] F. Calle-Vallejo, M.T.M. Koper, Accounting for Bifurcating Pathways in the Screening for $\mathrm{CO}_{2}$ Reduction Catalysts, ACS Catalysis. 7 (2017) 7346-7351.

[36] S.A. Akhade, W. Luo, X. Nie, A. Asthagiri, M.J. Janik, Theoretical insight on reactivity trends in $\mathrm{CO}_{2}$ electroreduction across transition metals, Catal. Sci. Technol. 6 (2016) 1042-1053.

[37] G. Kresse, J. Furthmueller, Efficient iterative schemes for ab initio total-energy calculations using a plane-wave basis set, Phys. Rev. B. 54 (1996).

[38] G. Kresse, D. Joubert, From ultrasoft pseudopotentials to the projector augmented-wave method, Phys. Rev. B. 59 (1999).

[39] J.P. Perdew, K. Burke, M. Ernzerhof, Generalized Gradient Approximation Made Simple, Phys. Rev. Lett. 78 (1997) 1396.

[40] M. Methfessel, A.T. Paxton, High-precision sampling for Brillouin-zone integration in metals, Phys. Rev. B. 40 (1989) 3616-3621.

[41] A. Rendón-Calle, S. Builes, F. Calle-Vallejo, Substantial improvement of electrocatalytic predictions by systematic assessment of solvent effects on adsorption energies, Applied Catalysis B: Environmental. 276 (2020) 119147.

[42] J.K. Nørskov, J. Rossmeisl, A. Logadottir, L. Lindqvist, J.R. Kitchin, T. Bligaard, H. Jónsson, Origin of the Overpotential for Oxygen Reduction at a Fuel-Cell Cathode, The Journal of Physical Chemistry B. 108 (2004) 17886-17892.

[43] L.P. Granda-Marulanda, A. Rendón-Calle, S. Builes, F. Illas, M.T.M. Koper, F. Calle-Vallejo, A Semiempirical Method to Detect and Correct DFT-Based Gas-Phase Errors and Its Application in Electrocatalysis, ACS Catalysis. 10 (2020) 6900-6907.

[44] J.K. Nørskov, N.D. Lang, Effective-medium theory of chemical binding: Application to chemisorption, Phys. Rev. B. 21 (1980) 2131-2136.

[45] N. Govindarajan, J.M. García-Lastra, E.J. Meijer, F. Calle-Vallejo, Does the breaking of adsorption-energy scaling relations guarantee enhanced electrocatalysis?, Current Opinion in Electrochemistry. 8 (2018) 110-117.

[46] N.B. Halck, V. Petrykin, P. Krtil, J. Rossmeisl, Beyond the volcano limitations in electrocatalysis - oxygen evolution reaction, Phys. Chem. Chem. Phys. 16 (2014) 13682-13688.

[47] X. Nie, M.R. Esopi, M.J. Janik, A. Asthagiri, Selectivity of $\mathrm{CO}_{2}$ Reduction on Copper Electrodes: The Role of the Kinetics of Elementary Steps, Angewandte Chemie International Edition. 52 (2013) 2459-2462.

[48] M.T. Tang, H. Peng, P.S. Lamoureux, M. Bajdich, F. AbildPedersen, From electricity to fuels: Descriptors for C1 selectivity in electrochemical $\mathrm{CO}_{2}$ reduction, Applied Catalysis B: Environmental. 279 (2020) 119384. 
[49] J. Hussain, H. Jònsson, E. Skùlason, Calculations of Product Selectivity in Electrochemical $\mathrm{CO}_{2}$ Reduction, ACS Catalysis. 8 (2018) 5240-5249.

[50] W. Luo, X. Nie, M.J. Janik, A. Asthagiri, Facet Dependence of $\mathrm{CO}_{2}$ Reduction Paths on Cu Electrodes, ACS Catalysis. 6 (2016) 219229.

[51] H.A. Hansen, J.B. Varley, A.A. Peterson, J.K. Nørskov, Understanding Trends in the Electrocatalytic Activity of Metals and Enzymes for $\mathrm{CO}_{2}$ Reduction to CO, The Journal of Physical Chemistry Letters. 4 (2013).

[52] R. García-Muelas, N. López, Statistical learning goes beyond the d-band model providing the thermochemistry of adsorbates on transition metals, Nature Communications. 10 (2019).

[53] A. Savin, R. Nesper, S. Wengert, T.F. Fässler, ELF: The Electron Localization Function, Angewandte Chemie International Edition in English. 36 (1997).

[54] H. Umeyama, K. Morokuma, The origin of hydrogen bonding. An energy decomposition study, Journal of the American Chemical Society. 99 (1977).

[55] A. Bagger, W. Ju, A.S. Varela, P. Strasser, J. Rossmeisl, Electrochemical $\mathrm{CO}_{2}$ Reduction: Classifying Cu Facets, ACS Catalysis. 9 (2019). 